\title{
THE DESIGN OF FUTURE THINGS: CAUTIOUS CARS
}

\author{
Donald A. Norman \\ Electrical Engineering \& Computer Science, \\ Cognitive Science \& Psychology \\ Nielsen Norman Group \\ Northwestern University \\ E-mail: www.jnd.org
}

\section{DISTINGUISHED KEYNOTE LECTURE}

I will discuss the increasing intrusion of intelligent devices into the automobile with both expected benefits and unexpected dangers.

The aviation industry knows a lot about the dangers of overautomation. The Human Factors and Control industry has long studied problems of operator control of automated equipment, including supervisory control. The issues here, however, are different: most studies of automation and intelligent devices look at industrial settings, with well-trained operators who do the same operations over and over again. In the automobile, we have ill-trained operators, with little understanding (and little interest in gaining understanding), who may have to react in seconds.

Full automation, along with full autonomy probably is inevitable, and it will provide significant safety benefits. But partial autonomy, partial automation can be confusing, frustrating and dangerous. For these in-between states, I propose that we do not allow partial solutions, but rather use the technology to augment our abilities in a symbiotic fashion. I propose an approach I call "natural interaction," where people and machines interact and communicate in ways that are natural, use environmental cues, and provide continual awareness of the other's activities without annoyance. This requires development of a science of natural interaction, using appropriate visual, haptic, and auditory fields that map gracefully between machine and environmental states and human perception. 